\title{
ANÁLISE DOS CONHECIMENTOS CIENTÍFICOS SOBRE MOVIMENTOS SOCIAIS E SUAS RELAÇÕES COM POLÍTICAS PÚBLICAS DE 2009 A 2019 NO BRASIL
}

\author{
ANÁLISIS DEL CONOCIMIENTO CIENTIIFICO SOBRE MOVIMIENTOS SOCIALES Y SUS \\ RELACIONES CON LAS POLÍTICAS PÚBLICAS DE 2009 A 2019 EN BRASIL
}

Lindon Johnson Pontes PORTELA ${ }^{1}$

Palavras-chave:

Pesquisa;

Saúde;

Pensamento crítico;

Democracia;

Educação

Keywords:

Investigación;

Salud;

Pensamiento crítico;

Democracia;

Educación

\section{RES U M O}

O objetivo proposto neste artigo é o de expor quais as relações entre os movimentos sociais e políticas públicas em artigos científicos nas bases de dados da Scopus e Web of Science, nos últimos dez anos no contexto brasileiro, ponderando sobre 5 eixos focais: i) artigos mais citados ii) fontes mais citadas; iii) autores mais citados; iv); relação dos autores com maiores cocitações; v) relação das palavras-chave mais usadas; vi). Após a busca e seleção dos documentos foi realizado análises no software VOSviewer que é uma ferramenta livre para a construção e visualização de redes e quadros bibliométricos. Foi demonstrado que as relações entre movimentos sociais e políticas públicas estão mais ligadas nas áreas de saúde coletiva, sociologia e educação rural, usando como fontes as revistas cientificas brasileiras de universidades públicas. A análise permitiu perceber que a ciência ainda está alinhada com os movimentos sociais no país, na busca de maior equidade social.

\section{RESU MEN}

El objetivo propuesto en este artículo es exponer las relaciones entre los movimientos sociales y las políticas públicas en artículos científicos en las bases de datos de Scopus y Web of Science, en los últimos diez años en el contexto brasileño, considerando 5 ejes focales: i) artículos ii) las fuentes más citadas; iii) autores más citados; iv); lista de autores con las más altas citaciones; v) lista de las palabras clave más utilizadas; vi). Después de buscar y seleccionar los documentos, los análisis se realizaron con el software VOSviewer, que es una herramienta gratuita para construir y visualizar redes y gráficos bibliométricos. Se demostró que las relaciones entre los movimientos sociales y las políticas públicas están más vinculadas en las áreas de salud colectiva, sociología y educación rural, utilizando las revistas científicas brasileñas de las universidades públicas como fuentes. El análisis mostró que la ciencia todavía está alineada con los movimientos sociales en el país, en busca de una mayor equidad social.

\footnotetext{
${ }^{1}$ Mestrando no Programa de Pós-graduação em Sociedade, Ambiente e Qualidade de Vida - PPGSAQ pela Universidade Federal do Oeste do Pará- UFOPA e Militante do Movimento Tapajós Vivo - MTV.
} 


\section{INTRODUÇÃO}

Os movimentos sociais são organizações de origem popular da sociedade civil organizada, nascendo de reivindicações justas. Nesse sentido, é válido, conhecer o funcionamento destes movimentos, que em sua essência tentam transformar as realidades no lugar do poder público ausente. As ações em conjunto com a sociedade organizada podem de forma espontânea influenciar as esferas municipais, estaduais e federais; um grande exemplo disso foi as diretas já, um movimento civil que manifestaram pelas eleições, assim como, a própria construção da constituição de 1988. Assim, é importante ponderar a temática dos movimentos sociais, pois sua discussão é importante para sabermos como está a vida sociopolítica do país (ALONSO, 2009).

Portanto, para Gohn (2008), os movimentos sociais devem ser vistos como ações sociais coletivas de caráter político e cultural que viabilizam formas distintas de organização popular e de se expressar suas carências sociais. No ato real, esses formatos adotam diferentes estratégias que variam da simples denúncia, para uma pressão social direta (mobilizações, marchas, concentrações, passeatas, distúrbios à ordem constituída, atos de desobediência civil, negociações e outras.). $\mathrm{Na}$ atualidade, os movimentos sociais basilares atuam utilizando os novos meios de comunicação e informação como a internet, sendo por meio das redes sociais, uma ferramenta para a circulação das suas pautas locais, regionais, nacionais e internacionais, na criação e desenvolvimento de novos saberes.

Dessa forma, o objetivo proposto neste artigo é o de expor quais as relações entre os movimentos sociais e políticas públicas em artigos científicos nas bases de dados da Scopus e Web of Science, nos últimos dez anos (2009-2019) no contexto brasileiro, ponderando analiticamente sobre 5 eixos focais: i) documentos/artigos mais citados ii) fontes mais citadas; iii) autores mais citados; iv); relação dos autores com maiores cocitações; v) relação das palavras-chave mais usadas; vi). 0 intuído da análise é o de demonstrar que a ciência ainda está alinhada com os movimentos sociais no país na busca de maior equidade social.

\section{METODOLOGIA}

O presente estudo se configura como uma pesquisa exploratória em publicações acadêmicas, buscando como objetivo realizar uma revisão com procedimentos descritos na literatura. Portanto, procurou 0 caminho da pesquisa bibliográfica, que de acordo Pádua (2004, p.14): "É fundamentada nos conhecimentos de biblioteconomia, documentação e bibliografia; sua finalidade é colocar o pesquisador em contato com o que já se produziu a respeito do tema de pesquisa, pesquisando e usando como referências importantes teóricos". Usou-se também como instrumento de pesquisa a observação bibliográfica que segundo Marconi e 
Lakatos (2006, p. 39.), "(...) utiliza os sentidos na obtenção de determinados aspectos da realidade. Consiste em ver, ouvir e examinar fatos ou fenômenos".

Desse modo, foi utilizada duas bases de dados da ciência internacional, chamada de Scopus e Web of Science (WoS). A realização da pesquisa se deu através de buscas por uso de palavras-chaves em inglês, pois, foram os termos que mais obteve resultados significativos, os termos utilizados foram: social movements And public policies And Brazil (Movimentos Sociais e Políticas Públicas E Brasil). Usando como critério de inclusão somente artigos científicos no período de 2009 a 2019, com trabalhos desenvolvidos dentro do território brasileiro, seguindo as recomendações de cada base de dados.

Diante disso, selecionou-se 132 artigos na WoS e 141 artigos na Scopus, após a busca e seleção dos documentos foi realizado uma análise no software VOSviewer que é uma ferramenta livre para a construção e visualização de redes e quadros bibliométricos, estas redes podem, por exemplo, incluir periódicos, pesquisadores ou publicações individuais e podem ser construídas com base em relações de citação, acoplamento bibliográfico, cocitação ou coautoria. As seguintes funções do software podem ser resumidas segundo Silva et al. (2020):

- Construção de mapas baseados em rede de dados, o VOSviewer pode ser usado para mapear as relações entre pesquisadores, organizações, países, palavras-chave ou termos. Estes termos podem ser conectados por coautoria, coocorrência, citação, acoplamento bibliográfico ou links de cocitação. As redes são elaboradas com dados das bases Web of Science, Scopus, Dimensões, PubMed, RIS ou Crossref JSON.

- $\quad$ O software exibe três tipos de visualização: em rede, sobreposição e densidade. Os detalhes dos mapas podem ser explorados por meio da função de zoom, rolagem e pesquisa.

Os resultados obtidos foram a partir da análise do programa como mencionado acima, chegando a construção de 10 figuras de redes bibliográficas: i) documentos/artigos mais citados ii) fontes mais citadas; iii) autores mais citados; iv); relação dos autores com maiores cocitações; v) relação das palavras-chave mais usadas; vi).

\section{RESULTADOS E DISCUSSÃO}

\subsection{Documentos/artigos mais citados}

Ao que se refere a Web of Science (WoS), o quadro abaixo mostra os documentos mais citados dos 132 documentos, sendo a análise com número mínimo de 15 citações nos artigos, resultando em 11 principais documentos citados (figura 1), porém, sem interconexões entre eles, ou seja, não gerou um mapa 
de redes. Observa-se que o artigo mais citado tem uma grande diferença entre o segundo mais citado quando comparado aos outros autores.

\begin{tabular}{|c|c|c|}
\hline Document & Citations $\vee$ & Links \\
\hline wittman (2009) & 51 & 0 \\
\hline parker (2009) & 29 & 0 \\
\hline hunter (2009) & 29 & 0 \\
\hline grangeiro (2009) & 26 & 0 \\
\hline loveman (2012) & 25 & 0 \\
\hline carter (2010) & 25 & 0 \\
\hline porto (2009) & 22 & 0 \\
\hline blanc (2012) & 20 & 0 \\
\hline $\operatorname{aran}(2009)$ & 19 & 0 \\
\hline amar (2009) & 18 & 0 \\
\hline molina (2015) & 16 & 0 \\
\hline
\end{tabular}

Figura 1- Documentos mais citados entre 2009-2019 na Web Of Science Fonte: Base de dados da WOS, 2020.

A mesma análise realizada acima, na base de dados da Scopus, com 141 artigos analisados, usando o mesmo número mínimo de 15 citações por documento/artigo, os resultados obtidos foram 10 documentos mais citados, porém, também sem conexões entre eles. Nota-se que diferente do quadro acima, está relação de artigos é mais equilibrada numericamente nas citações entre os autores (Figura 2).

\begin{tabular}{|l|r|r|}
\hline \multicolumn{1}{|c|}{ Document } & Citations $\checkmark$ & Links \\
\hline fleury s. (2009) & 34 & 0 \\
\hline loveman m. (2012) & 31 & 0 \\
\hline diniz s.g. (2015) & 27 & 0 \\
\hline dos santos n.r. (2013) & 27 & 0 \\
\hline grangeiro a. (2009) & 23 & 0 \\
\hline bosi m.l.m. (2011) & 22 & 0 \\
\hline canhos d.a.l. (2015) & 20 & 0 \\
\hline rocha d.g. (2014) & 20 & 0 \\
\hline porto m.f. (2009) & 20 & 0 \\
\hline arán m. (2009) & 19 & 0 \\
\hline
\end{tabular}

Figura 2 - Documentos mais citados entre 2009-2019 na Scopus. Fonte: Base de dados da SCOPUS, 2020.

Portanto, o documento mais citado dentro da base de dados WoS é o de Wittman (2009), com 51 citações e na Scopus é Fleury s. (2009), com 34 citações. Observa-se que são mulheres pesquisadoras/professoras, foi verificado que Hannah Wittman é professora do Instituto de Recursos, Meio Ambiente e Sustentabilidade da Universidade de Columbia nos Estados Unidos da América, com pesquisas sobre soberania alimentar, conservação da biodiversidade, agroecologia e economia. Já Sônia Fleury é pesquisadora e professora da Fundação Getúlio Vargas e em universidades na Argentina, atuando nas áreas de políticas públicas e seguridade social na saúde. 
Para Leta (2003), a ciência sempre foi vista como atividade realizada por homens, mas com o passar dos séculos gradativamente, houve mudanças no cenário do "patriarcado científico", obviamente, na luta das mulheres pelo direito de ter acesso à educação formal/acadêmica, isto é, por direitos políticos, buscando igualdade de gênero através de sua capacitação técnica/intelectual, por isso, foram aceitas pela comunidade científica para o desenvolvimento de carreiras como pesquisadoras na ciência.

A segurança alimentar e também nutricional tem ocupado a agenda pública no Brasil de forma crescente na construção de valores e práticas, com impactos diretos nas estruturas político-institucional de vários setores governamentais e da sociedade em geral, em percepções sobre 0 acesso aos alimentos, escassez, fome e qualidade sanitária como principais formas de insegurança alimentar, e mais ultimamente cresceu o debate cerca dos aspectos culturais, ambientais da saúde e nutrição, interrelacionado com seguridade de saúde pública (BURLANDY, 2008).

No que tange os aspectos dos artigos mais citados, sendo eles na temática de segurança alimentar e saúde pública e suas relações de movimentos sociais, Melucci (1996), em seu livro sobre códigos desafiadores, compreende que os movimentos sociais conseguem realizar diagnósticos sobre a realidade social, construindo propostas para novas políticas públicas. Agindo em redes, arquitetam ações coletivas, resistindo à exclusão social. Formando e desenvolvendo os atores locais da sociedade civil pela união de sujeitos sociais na atuação em rede, pois criam novas identidades a grupos antes dispersos e desorganizados. Os movimentos sociais dos anos 1980, como os atuais têm edificado os aspectos simbólicos e afirmativos por meio de discursos e práticas, estas ações tencionam em seus participantes sentimentos de pertencimento social. Aqueles que eram abandonados passam a se sentir incluídos em algum tipo de ação em um grupo funcional.

\subsection{Fontes mais citadas}

A figura 3, reflete sobre as fontes mais citadas dentro dos artigos analisados, das 84 fontes encontradas na WoS, com análise a partir de 2 documentos de ocorrência por fonte e 4 citações, o resultado obtido foram 9 fontes principais, sem link entre elas para geração de mapas em rede. As fontes mais citadas sâo: Ciencia \& Saúde coletiva, Journal of Rural Studies e Saúde e Sociedade.

Destaca-se que todas são revistas científicas, sendo as mais citadas duas brasileiras, que pertence a Associação Brasileira de Saúde Coletiva - ABRASCO, já, a que ficou abaixo é de um periódico internacional pertencente a Elsevier, a terceira é também brasileira e faz parte dos periódicos da Universidade de São Paulo-USP. 


\begin{tabular}{|l|r|r|r|}
\hline \multicolumn{1}{|c|}{ Source } & Documents & Citations & $\begin{array}{c}\text { Total link } \\
\text { strength }\end{array}$ \\
\hline ciencia \& saude coletiva & 12 & 75 & 1 \\
\hline journal of rural studies & 2 & 71 & 0 \\
\hline saude e sociedade & 12 & 41 & 0 \\
\hline latin american politics and society & 4 & 38 & 0 \\
\hline revista panamericana de salud publ... & 2 & 27 & 1 \\
\hline latin american research review & 2 & 25 & 0 \\
\hline latin american perspectives & 5 & 17 & 0 \\
\hline revista de saude publica & 2 & 11 & 0 \\
\hline social movement studies & 3 & 7 & 0 \\
\hline
\end{tabular}

Figura 3 -Relação das fontes mais citadas de 2009 a 2019 na base de dados Web of Science. Fonte: Base de dados da WOS , 2020.

Por outro lado a Figura 4, da base de dados da Scopus, foram analisadas 83 fontes, com o mínimo de 4 documentos de ocorrência e 7 citações por fonte, chegando ao resultado de 3 fontes mais citadas e com conexões relevantes, formando um mapa de redes.

Nesse sentido, o tamanho dos círculos se refere a quantidade de publicações, assim, ressaltando a sobreposição do círculo central da Revista Ciência e Saúde Coletiva. No que se referi as cores, elas são alusivas as temáticas, portanto, a vermelha tenciona sobre saúde, enquanto a verde faz alusão as questões com foco mais em sociedade. As revistas mais citadas são: Revista Ciência e Saúde Coletiva, Saúde e Sociedade e Cadernos de Saúde Pública (Figura 4).

\section{\& VOSviewer}

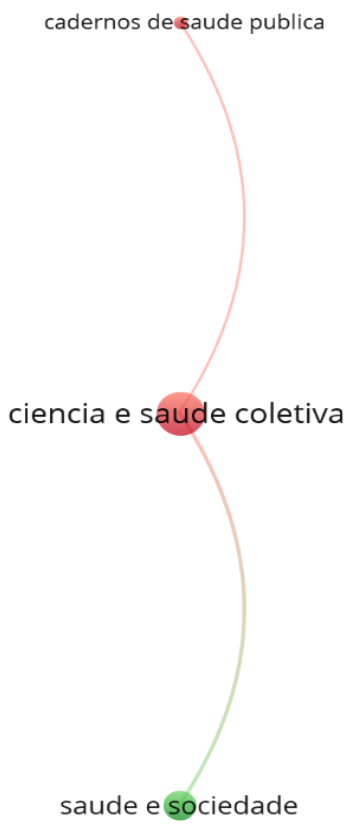

Figura 4 - Mapa das relações das fontes mais citadas de 2009 a 2019 na base de dados Scopus Fonte: Base de dados da SCOPUS, 2020. 
É evidenciado que as fontes mais citadas são da área da saúde, logo, as interconexões entre movimentos sociais e políticas públicas está mais ligado aos movimentos pela saúde coletiva e pública, pois os resultados corroboram para isso na análise das fontes mais citadas. De acordo com Bueno (2014), os desenvolvimentos de pesquisas no Brasil no âmbito acadêmico têm como alicerce a divulgação, ou seja, a propagação da ciência nos portais das universidades brasileiras, sendo um modo de avaliação de sua competência.

Ainda para o autor o tripé da universidade é o Ensino, Pesquisa e extensão, portanto, a universidade não pode ser uma entidade passivo na sociedade, por contrário deve realizar ações na construção de conhecimentos, investigações e prestação de serviços à comunidade, sendo um dos modos de retorno a sociedade do investimento público, assim sendo, desenvolver técnicas e tecnologias para o bem comum, se mantendo conectada com a sociedade civil organizada (BUENO, 2014).

Simionatto (1997) relembra que os maiores direitos sociais no âmbito de saúde pública no Brasil vieram por meio de muita luta e pressão social, estes direitos sociais nascem aqui de forma particularista, sendo adquiridos através da categoria profissional do trabalho e seguridade, na ocupação desempenhada no domínio do mercado, isto é, a própria Consolidação das Leis de Trabalho (CLT) é uma das formas de garantir a saúde no trabalho, no esforço de não haver insalubridade no desempenho das funções, como um certificado legal da cidadania política.

\subsection{Autores mais citados}

Diz respeito aos autores mais citados no corpo dos artigos no período de 2009 a 2019 na base de dados Scopus, na temática de movimentos sociais e políticas públicas, foram analisados 342 autores, com 0 mínimo de 2 documentos e 1 citação por autor, como mostra abaixo sobre a relação (Figura 5), porém sem conexões entre eles na geração de mapas, contudo, destaca-se os dois primeiros: bosi m. I. m.; paim j. s.

\begin{tabular}{|l|r|r|r|}
\hline \multicolumn{1}{|c|}{ Author } & Documents & Citations $\boldsymbol{*}$ & $\begin{array}{c}\text { Total link } \\
\text { strength }\end{array}$ \\
\hline bosi m.l.m. & 2 & 34 & 0 \\
\hline paim j.s. & 2 & 15 & 0 \\
\hline braga r. & 2 & 8 & 0 \\
\hline santana m.a. & 2 & 8 & 0 \\
\hline cruz p.j.s.c. & 2 & 6 & 0 \\
\hline abers r.n. & 2 & 3 & 0 \\
\hline rigotto r.m. & 2 & 2 & 0 \\
\hline
\end{tabular}

Figura 5- Autores mais citados dentro dos artigos da base de dados da Scopus Fonte: Base de dados da SCOPUS, 2020. 
Em pesquisas na plataforma do currículo Lattes, foi verificado que ambos os autores são da área da saúde, especialmente na área de saúde pública e saúde coletiva. Assim, Maria Bosi faz parte de três unicidades, tais como: Universidade Estadual de Campinas, Universidade do Estado do Rio de Janeiro e Universidade Federal do Ceará. Enquanto Jairnilson Paim é professor e pesquisador vinculado a Universidade da Bahia.

Em congruência com o que foi analisado acima, porém a base de dados da WoS, analisou 297 autores, se sobressaindo entre eles: wittman, hannah e paim, jairnilson silva, porém sem conexões para geração de mapas em rede (Figura 6).

\begin{tabular}{|l|r|r|r|r|}
\hline \multicolumn{1}{|c|}{ Author } & Documents & Citations $\boldsymbol{V}$ & $\begin{array}{c}\text { Total link } \\
\text { strength }\end{array}$ \\
\hline wittman, hannah & 2 & 53 & 0 \\
\hline paim, jairnilson silva & 2 & 13 & 0 \\
\hline gibson, christopher I. & 3 & 6 & 0 \\
\hline grisa, catia & 2 & 3 & 0 \\
\hline
\end{tabular}

Figura 6 - Autores mais citados dentro dos artigos da base de dados da Web os Science. Fonte: Base de dados da WOS, 2020.

Chegou-se a duas conclusões, a primeira é que o tema de saúde coletiva está em maior relevância entre os autores mais citados em trabalhos desenvolvidos no Brasil. O segundo ponto a ser ponderado é sobre as temáticas de segurança alimentar e meio ambiente, ainda estão no rol de discussões, por serem temas intensos como a saúde no período de 2009 a 2019 nas discussões entre políticas públicas e movimentos sociais.

No âmbito da saúde coletiva, ela se configura como um campo de conhecimento interdisciplinar nas ciências sociais da saúde, epidemiologia e gestão/planejamento da saúde. A saúde coletiva teve influências da própria democratização do estado brasileiro, em especial a reforma sanitária, nesses processos do autoritarismo da ditadura militar, para a retomada dos direitos humanos, surgiu uma aliança entre saúde e democracia (OSMO; SCHRAIBER, 2015).

Dessa forma, para Campos (2000), ao dar valor a aspectos sociais na saúde, buscou na construção das premissas filosóficas as referências em uma abordagem histórico-estrutural do social e não apenas adquiriu uma aparência dividida/estratificada da sociedade como ela é, tal como a abordagem separada de elementos do meio ambiente e da própria população.

No que diz respeito a visão interdisciplinar da saúde, como uma visão ancorada no social, não apenas a resumindo a condições biológicas, mas sim a uma complexidade de condições, sendo assim, de acordo com Rosen (1983, p. 51-52), menciona alguns princípios para uma prática da medicina social: 
O primeiro destes princípios é que a saúde das pessoas é um assunto societário direto e que a sociedade tem a obrigação de proteger e assegurar a saúde de seus membros [...]. 0 segundo, como notou Neumann, é que as condições sociais e econômicas têm um importante e - em muitos casos - crucial impacto sobre a saúde e a doença e que estas relações devem ser submetidas à investigação científica [...]. O terceiro princípio, que se segue logicamente, é que os passos tomados para promover a saúde e combater a doença devem ser tanto sociais como médicos.

Consequentemente, a mobilização/articulação política é o que determina como os processos coletivos serão traduzidas em demandas a serem reivindicadas por intermédio dos movimentos sociais, também conjuntamente no processo que constitui as relações entre grupos de interesses com trajetórias historicamente conflituosas. Nas últimas décadas os movimentos de resistência cujo ponto central da articulação se refere a aspectos de identidade como étnico racial, de gênero, de nacionalidade, dentre outras, que se somam às questões abordadas mais tradicionalmente pelas organizações unicamente relacionadas à luta de classes (MCDONALD, 2006).

\subsection{Relação dos autores com maiores cocitações}

No que constituiu a análise sobre os autores com maiores cocitações nos artigos, se destacaram 10 autores dos 3850 autores analisados, sendo o número mínimo de 10 citações por autor, estabelecendo um mapa de rede entre 5 dos autores para a construção das correlações (Figura 7) que mostra as cocitações na base de dados da WoS.

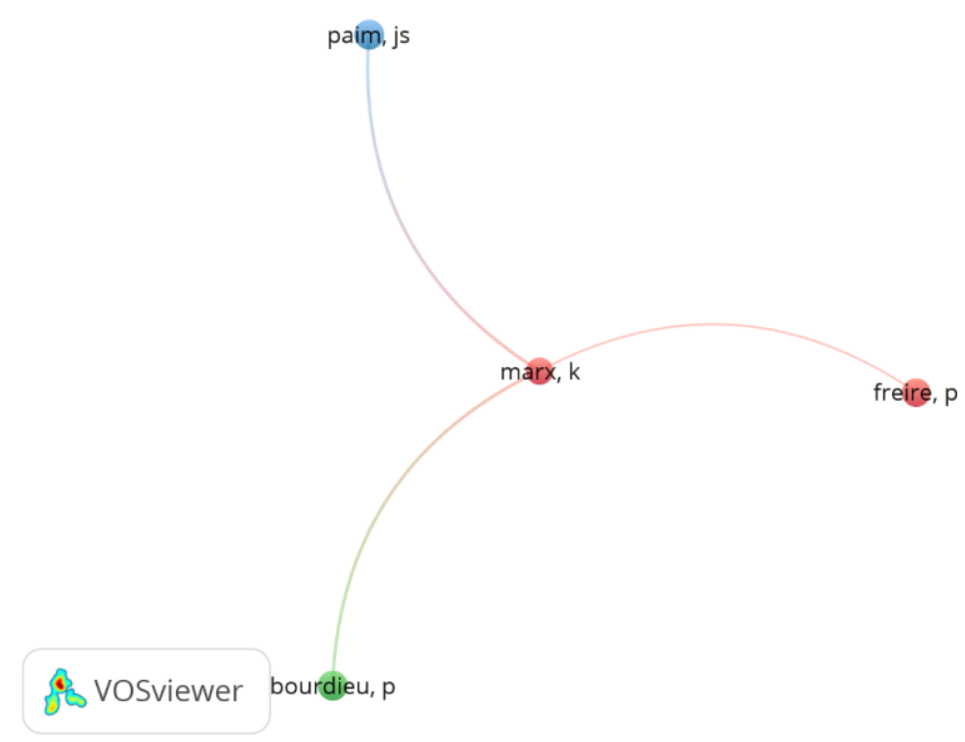

Figura 7 - Autores com maiores cocitações de 2009 a 2019 na base de dados da Web of Science.

Fonte: Base de dados da WOS, 2020. 
Nota-se no mapa a figura central de Marx, circundado por Paim, Freire e Bourdieu, no que consta o tamanho das esferas, significa que a densidade de cocitação é a mesma para todos, o que muda são suas colorações, sendo elas: azul (paim.js), vermelho (marx, k; freire, p) e verde (bourdieu, p), a cor azul com temática da área de saúde, vermelho nas temáticas sociológicas e verde mais tendencioso para educação.

Já o mesmo tipo de análise de cocitação na base de dados Scopus, sendo analisados 4628 autores, com o mínimo de 12 citações por autor, resultando em 9 autores mais citados. Destaca-se no mapa duas cores predominantes, vermelho com os autores: paim js; foucult, m; santos, m. e marx, k (círculo sem nome); verde: freire, p; pertersen, p e bellon, s., (Figura 8).

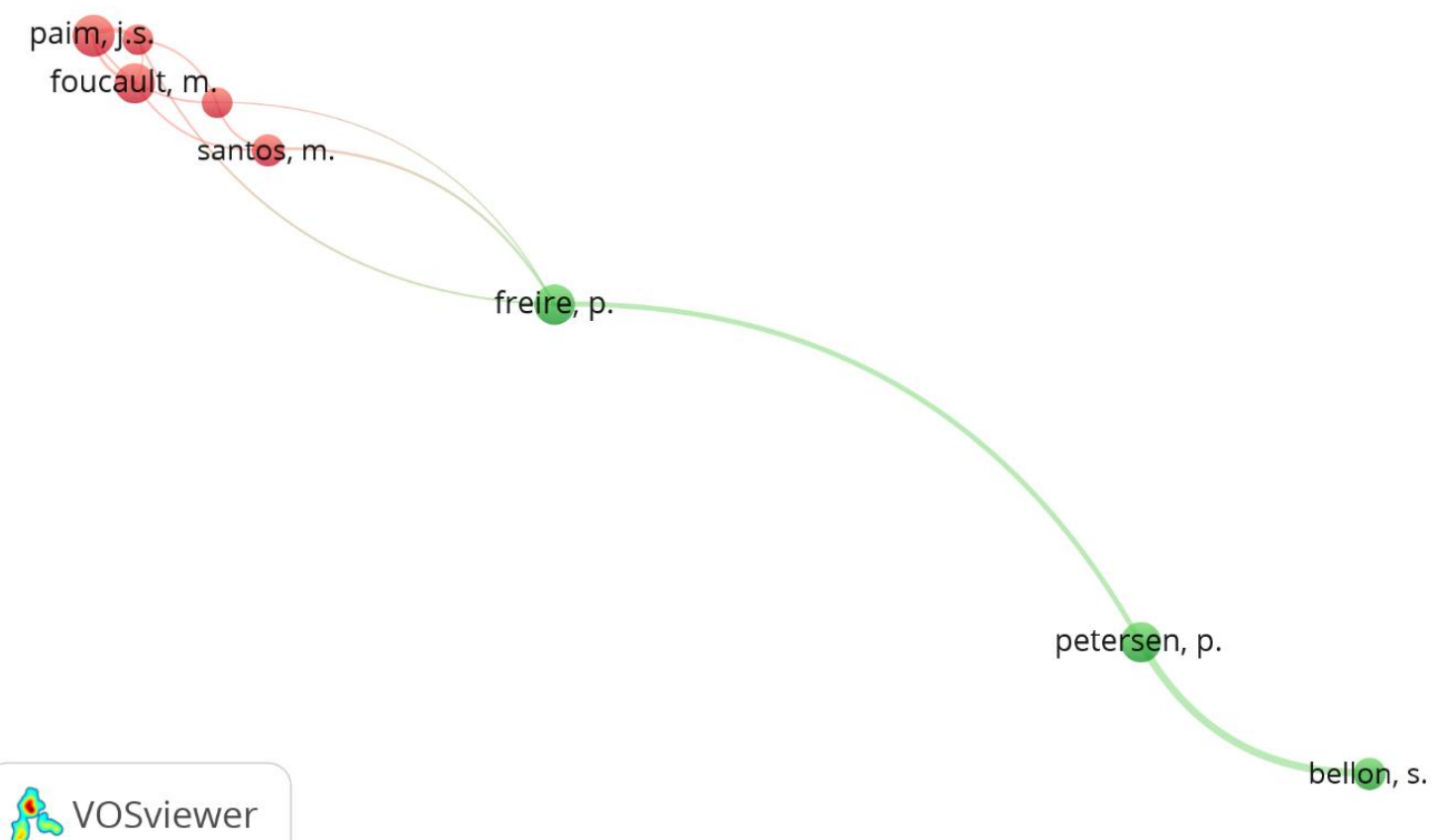

Figura 8 - Autores com maiores cocitações de 2009 a 2019 na base de dados da Scopus Fonte: Base de dados da SCOPUS , 2020.

É importante ressaltar que os círculos com a cores vermelhas são autores da área sociológica e de saúde, visto que são reconhecidos nas ciências humanas, tais como: Michel Foucault, Milton Santos e Karl Marx, na área de saúde coletiva se destaca: Jairnilson Paim. A cor verde com autor de ligação Paulo Freire, após ele Paulo Petersen e Stéphane Bell, está numa discussão na área de agroecologia. A partir dos resultados obtidos nas duas bases de dados, fica evidente os nomes de Marx, Freire e Paim se destacam.

Na ideia de Braga (2015), sobre a relevância do marxismo para os movimentos sociais, frisa que Karl Marx foi primordial para a história do pensamento revolucionário, principalmente, entre a consolidação de dois 
conceitos filosóficos, tais como, o "de classe social", sendo a divisão da sociedade em classificações daqueles que detém e os que não detêm os meios de produção (capital). O segundo se refere a "luta de classes", como uma força social ao combate do capitalismo, na tomada dos bens de produção pelos trabalhadores e de distribuição de renda, assim, a apropriação destes termos, deram base teórica para ações concretas dos movimentos sociais.

Nessa perspectiva, o pensamento crítico de Paulo Freire também está imbricado nas ideias de Marx, principalmente na terminologia de Práxis pedagógica, como uma ação-reflexão-ação inteiramente crítica ao modelo econômico e educacional, na formação de alunos alienados e meramente ferramentas do capital, como fonte de mão de obra. As ideias de Freire vão para além da sala de aula, fazendo uma análise ao modelo civilizatório, das relações entre opressores e oprimidos, se tornando um dos autores mais citados (FERNANDES, 2016; ZANELLA, 2010).

A saúde coletiva sendo constituída nos limites do biológico e social tem como tarefa investigar, compreender e entender os determinantes da produção social das doenças e das organizações da sociedade e dos serviços de saúde, de maneira crítica ao sistema não apenas de saúde, também econômico, assim por dizer, o campo das pesquisas sobre saúde pública é fértil, não apenas na apreensão da ciência, mas em tentativas de realizar mudanças sociais, através da atuação de pesquisadores (NUNES, 1994).

Diante disso, Vilela e Mendes (2003, p. 529), faz o ponderamento de que,

Tal complexidade se acentua quando procuramos entender saúde no âmbito coletivo, cujo objeto envolve o biológico e o social, o indivíduo e a comunidade e ainda, a política social e econômica. Como campo político, é um espaço em que a articulação cooperativa entre as disciplinas constitui-se $11 \mathrm{em}$ "um campo de correlação de forças", relacionado à consciência social e política. Para se chegar a uma Saúde Coletiva é necessário um esforço interdisciplinar que tem como consequência uma abertura conceitual.

Na interpretação de Paim (2018), a saúde pública, sustentado no Sistema Único de Saúde - SUS, sendo uma garantia constitucional, inspirado em valores de igualdade e democracia, é a forma mais didática de se conhecer as correlações entre saúde coletiva, numa dimensão interdisciplinar, com agentes sociopolíticos sendo atores principais de reivindicação, na dinamicidade de pensamentos críticos, na bipolaridade entre burguesia e proletariado, por isso, a saúde precisa ser defendida, e quem pode fazer isso é a sociedade organizada. 


\subsection{Relação das palavras-chave mais citadas}

No aspecto das palavras-chave mais citados nos artigos analisados na WoS, foram de 534 termos, com o número de mínimo de 5 ocorrências, resultando em 15 termos (figura 9), assim, os círculos maiores representam os termos com mais intensidade, as cores representam os aspectos distintos de cada temática.

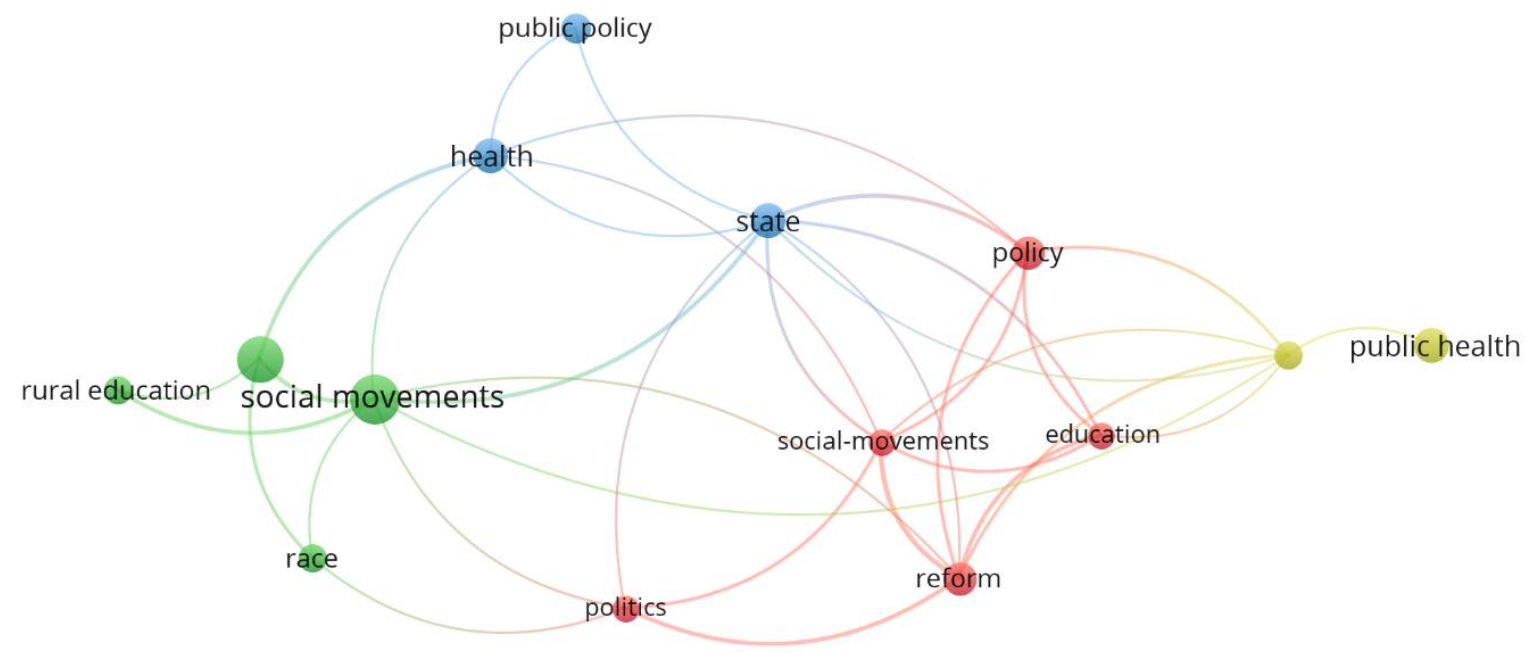

\section{VOSviewer}

Figura 9 - Análise das palavras-chave mais citadas no período de 2009 a 2019 na base de dados Web of Science

Fonte: Base de dados da WOS, 2020.

A cor azul representada cos termos: health (saúde), state (estado) e public policy (política pública); a cor verde: social movements (movimente social), rural education (educação rural) e race (corrida); a vermelha: policy (política), social movements (movimentos sociais), education (educação), politics (política) e reform (reforma); amarelo: public health (política pública). Dentre todos os citados se sobressaem: Saúde, política pública, movimentos sociais e educação.

Já a análise das palavras-chave na base de dados da Scopus, dos 733 termos, com o número mínimo de 10 ocorrências de termos, chegou ao resultado de 13 palavras (figura 10). Como mencionado acima, os círculos mais densos representam os mais citados, com duas cores em destaque, vermelho com os termos: organizatin and management (organização e gestão), human (humano), public health (saúde pública), health care policy (cuidados de saúde pública), health policy (saúde pública); verde: public policy (políticas 
públicas) e social movements (movimentos sociais). Contudo o que mais vale destaque são as palavras: humano, cuidados de saúde pública e políticas públicas.

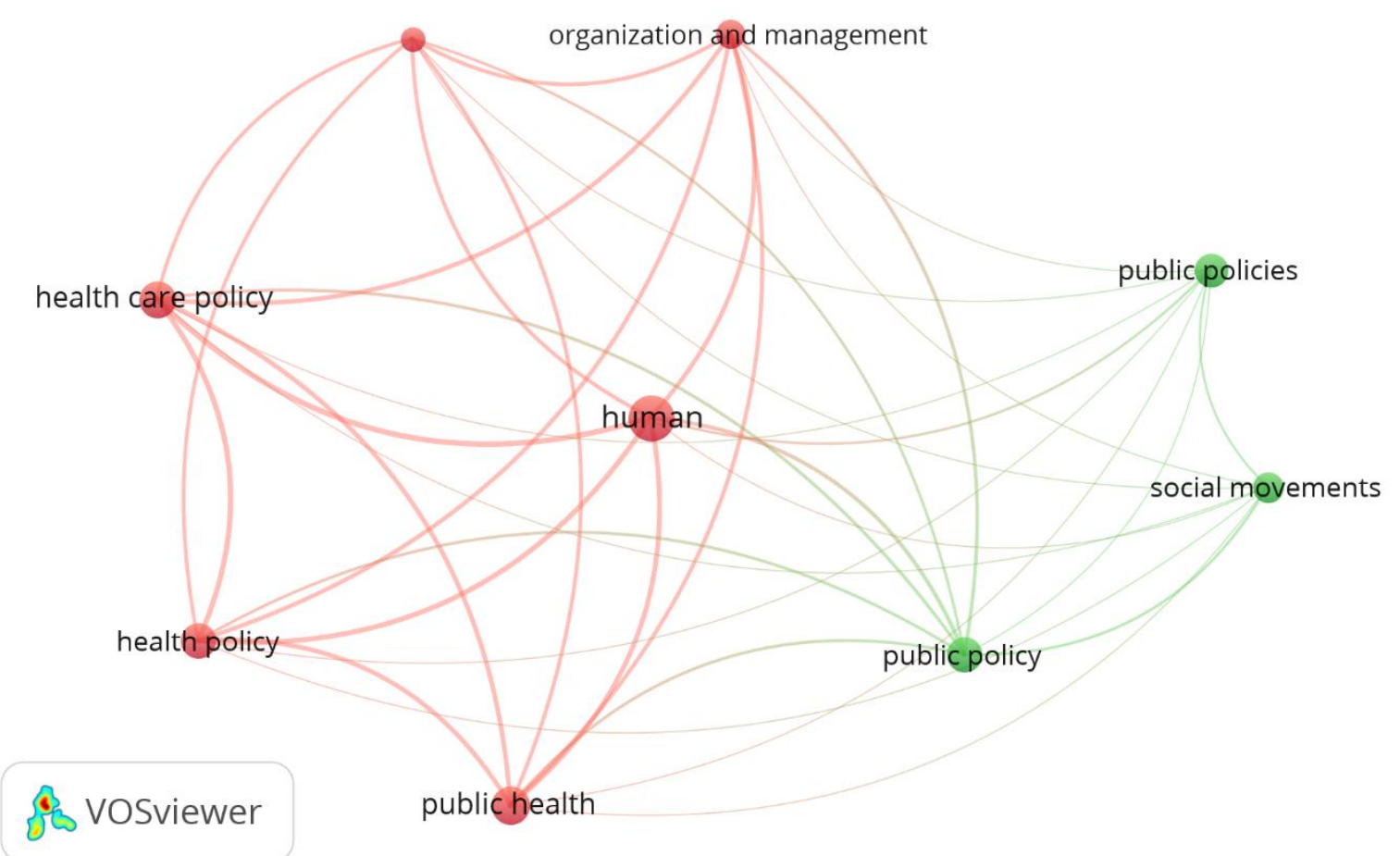

Figura 10 - Análise das palavras-chave na base de dados da Scopus no período de 2009 a 2019 Fonte: Base de dados da SCOPUS, 2020.

No contexto geral das palavras-chave, percebe-se a temática de saúde, entrelaçada com movimentos sociais, nessa perspectiva, Bravos e Menezes (2010), expõe que para compreendermos o movimento de qualidade de saúde no Brasil e sua importância na história da política de saúde brasileira, faz-se necessário resgatar, de forma breve, a trajetória histórica da saúde no país e o contexto que situa cada momento de mudança da referida política. Assim sendo, esse item procura enfocar o início da intervenção do Estado na política de saúde brasileira, nos anos 1920 até os dias atuais.

O sentido de saúde no período de 1970 e 1980, se expandiu exponencialmente, curiosamente numa crise de saúde, floresceu um debate entre profissionais, teóricos, organizações, políticos e a população, sendo a ampliação da reforma sanitária, modelando uma nova maneira de perceber à saúde, num modelo de saúde coletiva, por conseguinte, os movimentos sociais que agitaram o Brasil, fizeram emergir na saúde coletiva um posicionamento político referente ao modelo de saúde do estado nacional (CONCEIÇÃO, 2017).

Portanto, os movimentos sociais sempre existiram, e sempre existirão. Isto porque representam grandes forças de articulação social, que aglutinam as pessoas não de forma desorganizada, mas como 
campo de atividades e experimentação social e política, e essas atividades são fontes geradoras de criatividade e inovações socioculturais. A experiência e conhecimento da qual são portadores não advém de forças congeladas em outrora, embora este tenha importância crucial ao criar uma memória que, quando resgatada, dá sentido às lutas sociais do presente (GONH, 2011).

Visto que o Brasil é um estado que dificulta a construção de sujeitos politizados, relacionados dentro da estrutura social capitalista estreitamente imbricada a economia, o governo intencionalmente realiza a desestruturação das políticas de saúde pública seja por atos corruptos ou para privatização da saúde, surgindo assim intensos choques e conflitos ideológicos com a minoria/massa de trabalhadores, sobretudo, quando se fala em doenças, ou seja, no desequilíbrio do estado saúde da população (STOTZ, 1994).

Assim, para Poupeau (2007), A experiência recria-se cotidianamente, na adversidade das situações que enfrentam, assim, afirmava-se que os movimentos são o espírito, o abalar da sociedade, se expressando com energias positivas de resistência ao velho que oprime ou de constituição do novo que liberte. Energias sociais antes dispersas são canalizadas e potencializadas por meio de suas práticas em "fazeres propositivos", em ações pensadas.

$\mathrm{Na}$ compreensão de Bravo e Menezes (2010), expõe que os movimentos conseguem realizar diagnósticos sobre as realidades sociais, constroem propostas, em vista de política pública. Agindo em redes, arquitetam ações coletivas que agem como resistência à exclusão e lutam pela inclusão social. Formam e desenvolvem o chamado fortalecimento de atores locais da sociedade civil organizada à medida que criam sujeitos sociais para essa atuação em rede. Tanto os movimentos sociais de outrora como os atuais têm edificado aspectos simbólicos afirmativas por meio de discursos e práticas. Ao realizar essas ações, tencionam em seus participantes sentimentos de pertencimento social. Aqueles que eram abandonados passam a se sentir incluídos em algum tipo de ação de um grupo funcional.

Entretanto, para Touraine (1984), a primeira década deste século trouxe, de forma bastante conflitante, o retorno do ator social nas ações coletivas que se difundem na maioria dos países da América Latina, pois houve um radical processo de reconstrução democrática e o ressurgimento de lutas sociais tidas décadas atrás como tradicionais, a exemplo de movimentos étnicos (indígenas), associados ou não a movimentos nacionalistas como o dos bolivarianos, na Venezuela. Algumas se baseiam em utopias como 0 "bem viver" dos povos andinos da Bolívia e do Equador, e vem alterar-se em propostas de gestão do Estado, um Estado considerado pluricultural porque é composto por povos de diferentes etnias, que excedem os territórios e fronteiras do Estado/nação propriamente dito.

Desse modo, Dupas (2005) contextualiza os conflitos brotadas na atualidade entre segmentos de interesse público e privado. As transformações sociais decorrentes da reforma do Estado e da expansão do neoliberalismo são consideradas fatos históricos que acirraram o contexto socioeconômico de modo que as contradições afloram no individualismo e na descrença em relação de que o Estado promova a inclusão 
igualitária dos variados segmentos no âmbito das ações governamentais. Exatamente por conta dessa busca por representatividade historicamente tem sido verificada uma fragmentação crescente nas lutas sociais, cada dia mais voltadas para demandas específicas.

\section{CONCLUSÃO}

Conclui-se, a pesquisa, evidenciando a relevância que os movimentos sociais têm nas políticas públicas, sejam eles novos movimentos sociais ou não, servem para a consolidação e manutenção da democrática, na tentativa de mais equidade social, na medida em que levaram não só um grupo de pessoas a lutarem por ela, mas várias pessoas de diversas classes sociais a resistirem pelos seus direitos constitucionais, estabelecendo um espaço próprio para discutirem ações e pautas de reivindicações de gênero, de raça, credo, educação, meio ambiente e outros.

Retomo ao objetivo central do trabalho que é o de fazer uma revisão teórica sobre artigos que tenham como tema os movimentos sociais e políticas públicas no Brasil nos últimos dez anos (2009 - 2019), no sentido de perceber o quanto os movimentos são importantes como instrumentos de criação de políticas e fiscalização destes, assim como, ampliar a noção da pesquisa sobre tal temática, por organizações ligadas a universidades em pesquisas. Nota-se, sobretudo, que os termos mais citados têm em sua essência ligação direta com o que mais de público tem no sistema brasileiro, a saúde, se sobressaiu como maiores citações, autores publicações nestes últimos anos, em seguida a educação, como fatores cruciais no campo de pesquisas e na defesa por mais inclusão destas políticas, de modo mais integralizado e coletivo, para a garantia da dignidade humana e qualidade de vida.

Destaca-se que estes movimentos são dinâmicos, se modificando com o passar dos anos, suas reivindicações se alteram de acordo com as transformações sociais existentes, mas não deixam de lutar por um mundo melhor, a cada ano, suas pautas se alteram, mas o desejo por equidade social permanece firme. Assim dizendo, o que aponta o estudo são as reivindicações por uma saúde mais humana, numa cosmovisão multidisciplinar e interdisciplinar, pautada na educação rural, agroecologia e gestão da saúde.

O campo acadêmico está ativo em analisar os movimentos e suas relações com políticas públicas, no total dos trabalhos analisados sendo eles, 273 artigos no território brasileiro, mostrando que as realidades sociais do Brasil são estudadas por cientistas brasileiros e por fontes brasileiras, expondo que o contexto brasileiro é cheio de particularidades, mas têm em sua essência pessoas aguerridas e com uma causa muito bem definida e organizada na defesa de políticas públicas. 


\section{REFERÊNCIAS}

ALONSO, A. As teorias dos movimentos sociais: um balanço do debate. Lua Nova, São Paulo, n. 76, p. 4986, 2009.

BURLANDY, L. Segurança alimentar e nutricional e saúde pública. Cad. Saúde Pública, Rio de Janeiro, v. 24 , n. 7, p.1464-1465, 2008

BUENO, W. C. A Divulgação da Produção Científica no Brasil: A Visibilidade da Pesquisa nos Portais das Universidades Brasileiras. R. Ação Mediática, n. 7, 2014.

BRAGA, R. A pulsão plebeia: trabalho, precariedade e rebeliões sociais. São Paulo: Alameda, 2015.

BRAVO, M. I.; MENEZES, J. S. B. de. Movimentos sociais, saúde e trabalho. Rio de Janeiro:

ENSP/Fiocruz, 2010.

CONCEICAO, H. R. M.. Saúde Coletiva e movimento social. Rev. psicol. polít., São Paulo, v. 17, n. 39, p. 247-260, ago. 2017.

CAMPOS, G. W. S. Saúde pública e saúde coletiva: campo e núcleo de saberes e práticas. Ciênc. saúde coletiva. vol.5, n.2, pp.219-230. 2000.

DUPAS, G. Tensões contemporâneas entre o público e o privado. São Paulo: Paz e Terra. 2005.

FERNANDES, S. Pedagogia crítica como práxis marxista humanista: perspectivas sobre solidariedade, opressão e revolução. Educ. Soc., Campinas, v. 37, n. 135, p. 481-496, 2016.

GONH. M. G Movimentos sociais na contemporaneidade. Revista Brasileira de Educação. vol.16 no.47 Rio de Janeiro May/Aug. 2011.

O protagonismo da sociedade civil: movimentos sociais, ONGs e redes solidárias. 2. ed. São Paulo: Cortez, 2008. Sociologia dos Movimentos Sociais.

2. ed. São Paulo: Cortez Editora, 2014.

LETA, J. As mulheres na ciência brasileira: crescimento, contrastes e um perfil de sucesso. Estudos Avançados. vol.17 no.49 São Paulo Sept./Dec. 2003.

MARCONI, E .; M. LAKATOS , M. A. Técnicas de pesquisa. 6. ed. São Paulo: Atlas. 2006.

MCDONALD, K.. Global Movements: Action and Culture. Oxford: Blackwell, 2006.
MELUCCI, A. Challenging codes: collective action in the information age. Nova lorque: Cambridge University Press, 1996.

NUNES, E. D. Saúde coletiva: história de uma ideia e de um conceito. Saude soc. vol.3, n.2, pp.5-21, 1994.

OSMO, A.; SCHRAIBER, L. B. O campo da Saúde Coletiva no Brasil: definições e debates em sua constituição. Saúde Soc. São Paulo, v.24, supl.1, p.205-218, 2015.

PAIM, J. S. Sistema Único de Saúde (SUS) por 30 anos. Ciênc. saúde coletiva, Rio de Janeiro, v. 23, n. 6 , p. 1723-1728, junho de 2018.

PÁDUA, Elisabete Matallo Marchesini de. Metodologia da pesquisa: Abordagem teórico-prática/Elisabete Matallo Marchesini de Pádua. 10. ed. Campinas: Papirus, 2004.

POUPEAU, F. Dominación y movilizaciones .Córdoba: Ferreyra Editor, 2007.

ROSEN, G. A evolução da medicina social. In: NUNES, E. (Org.). Medicina social: aspectos teóricos e históricos. São Paulo: Global, 1983. p. 25-82.

SIMIONATTO, I. Caminhos e descaminhos da política de saúde no Brasil. Revista Inscrita, Brasília: CFESS, n. 1, p. 15-20, 1997.

SILVA, F. F. et al., análise bibliométrica sobre políticas públicas. Revista de políticas públicas. v. 23 , n. 2 , 2019.

STOTZ, E. N. Social Movements and Health: Notes for a Debate. Cad. Saúde Públ., Rio de Janeiro, v. 10, n. 2, p. 264-268, Apr/Jun, 1994.

TOURAINE, A. Le retour de l'acteur. Paris: Fayard, 1984.

VILELA, E. M; MENDES, I. J. M. Interdisciplinaridade e saúde: estudo bibliográfico. Rev. Latino-

Am. Enfermagem , Ribeirão Preto, v. 11, n. 4, p. 525531, agosto de 2003.

ZANELLA, J. L. Considerações sobre a filosofia da educação de Paulo Freire e o Marxismo. Quaestio Revista de Estudos em Educação, Sorocaba, v. 9, n. 1, p. 101-122, 2010. 